\title{
Article
}

\section{Eutectic mixtures based on polyalcohols as sustainable solvents: Screening and characterization}

Liliana P. Silva, Mónia A.R. Martins, João H. Conceição, Simao P. Pinho, and Joao A.P. Coutinho

ACS Sustainable Chem. Eng., Just Accepted Manuscript • DOI: 10.1021/

acssuschemeng.0c05518 - Publication Date (Web): 10 Sep 2020

Downloaded from pubs.acs.org on September 11, 2020

\section{Just Accepted}

"Just Accepted" manuscripts have been peer-reviewed and accepted for publication. They are posted online prior to technical editing, formatting for publication and author proofing. The American Chemical Society provides "Just Accepted" as a service to the research community to expedite the dissemination of scientific material as soon as possible after acceptance. "Just Accepted" manuscripts appear in full in PDF format accompanied by an HTML abstract. "Just Accepted" manuscripts have been fully peer reviewed, but should not be considered the official version of record. They are citable by the Digital Object Identifier (DOI®). "Just Accepted" is an optional service offered to authors. Therefore, the "Just Accepted" Web site may not include all articles that will be published in the journal. After a manuscript is technically edited and formatted, it will be removed from the "Just Accepted" Web site and published as an ASAP article. Note that technical editing may introduce minor changes to the manuscript text and/or graphics which could affect content, and all legal disclaimers and ethical guidelines that apply to the journal pertain. ACS cannot be held responsible for errors or consequences arising from the use of information contained in these "Just Accepted" manuscripts. 


\title{
Eutectic mixtures based on polyalcohols as sustainable solvents: Screening and characterization
}

\author{
Liliana P. Silva ${ }^{\dagger}$, Mónia A. R. Martins ${ }^{\dagger}$, João H. Conceição ${ }^{\dagger}$, Simão P. Pinho* and João \\ A. P. Coutinho ${ }^{\dagger, *}$ \\ ${ }^{\dagger}$ CICECO - Aveiro Institute of Materials, Campus Universitário de Santiago, Department \\ of Chemistry, University of Aveiro, 3810-193 Aveiro, Portugal; \\ ¥Mountain Research Center - CIMO, Campus de Santa Apolónia, Polytechnic Institute \\ of Bragança, 5301-855 Bragança, Portugal. \\ *Corresponding author: jcoutinho@ua.pt. Phone: +351 234370200. Fax: +351 234370084.
}




\begin{abstract}
Despite some promising potential applications of eutectic systems containing choline chloride and a polyalcohol, a detailed investigation of the thermodynamic behavior of these systems is still missing. In this work, the solid-liquid equilibria phase diagrams of binary systems containing choline chloride, and one from six different polyalcohols (ethylene glycol, 1,3-propanediol, glycerol, meso-erythritol, xylitol and sorbitol), were measured in the full composition. Excepting the mixtures with glycerol or ethylene glycol a quasi-ideal behavior in the $[\mathrm{Ch}] \mathrm{Cl}$ solubility curve is observed. In the polyalcohol solubility curve, the mixtures present small negative deviations from ideality, excepting $[\mathrm{Ch}] \mathrm{Cl}+$ ethylene glycol, which is slightly positive. The solid-liquid phase diagrams show a large liquidus composition window, and not a fixed stoichiometry for the eutectic points, where the mixtures can be used as solvents close, or below, room temperature. Aiming at their application, viscosities and densities were measured at the eutectic point in the temperature range from 278.15 to $373.15 \mathrm{~K}$. All systems present densities and viscosities higher than water, which are directly related to the strong interactions between the components. Solvatochromic parameters were measured to characterize the solvents and they show how to achieve solvent tunability by varying the polyalcohol mole fraction.
\end{abstract}

Keywords: Eutectic solvents, solid-liquid equilibrium, phase diagrams, density, viscosity, solvatochromic parameters. 


\section{Introduction}

Over the years, volatile organic compounds have been widely used as solvents. These are mainly composed of low molecular weight petrochemical derivatives and alcohols, which show often drawbacks such as volatility, flammability, toxicity, and in many cases, poor biodegradability. ${ }^{1}$ In the last decade, the concept of sustainable development has impacted different industries and the way of thinking processes and methods, especially due to the properties of the solvents used. Alternative solvents such as ionic liquids, supercritical fluids, and biomass-based solvents, among others, have been sought. ${ }^{2,3}$ However, these also present several drawbacks regarding the large-scale use, such as their thermal and chemical instability, high cost, advanced equipment requirements, and/or life-cycle assessment. In this sense, the replacement of traditional organic solvents is crucial, and mixtures of natural compounds have emerged as a green sustainable alternative. The potential solvent character of eutectic and deep eutectic solvents (ES and DES, respectively) have been investigated as an alternative to conventional organic solvents due to their promising properties and industrial applications. ${ }^{4,5}$ The possibility of having solvents of lower viscosity at room temperature, or relatively low operating temperatures, led researchers to investigate different combinations of hydrogen bond acceptors (HBA) and hydrogen bond donors (HBD) as constituents of ES. ${ }^{6}$

Regarding the interest of the industrial and scientific communities for new greener solvents, the eutectic systems present several advantages: low toxicity, high biodegradability, negligible volatility, and can be considered as having less impact on the environment than other solvents. ${ }^{1,6}$ However, the green character of any eutectic mixtures relies on the use of environmentally friendly components. These include non-toxic quaternary ammonium salts as HBA and HBD such as amines, sugars, alcohols, sugar alcohols, polyalcohols, and organic

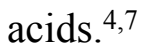

One of the most ubiquitous HBA is choline chloride $([\mathrm{Ch}] \mathrm{Cl})$, an essential nutrient and additive in animal feed. Mixtures containing $[\mathrm{Ch}] \mathrm{Cl}$ are generally biodegradable. Being a strong HBA presenting a relatively small (4300 $\left.\mathrm{J} \mathrm{mol}^{-1}\right)^{6}$ melting enthalpy, it usually shows a very steep solid-liquid equilibrium curve. ${ }^{8}$ On the other hand, polyalcohols are widespread materials derived from natural sources presenting non-corrosive and non-toxic characteristics and are often used as HBD. ${ }^{11}$ Among them, glycerol and ethylene glycol (EG) are widely studied due to their ability to form liquid mixtures in a large composition range namely with choline chloride, or urea. ${ }^{10-14}$ 
Sustainable ES composed of cheap biodegradable polyalcohols and choline chloride have been commonly used in DES formulations, as they allow numerous applications namely on chemical, pharmaceutical, and material fields. These eutectic solvents were proposed as extraction media for azeotropic mixtures, ${ }^{15}$ to extract flavonoids as well as purification agents of biodiesel. ${ }^{16}$ In this respect, Abbott and co-workers ${ }^{16}$ reported glycerol-based DES as an efficient extraction media for glycerol from biodiesel based on rapeseed or soybean oil, while Hayyan et al. ${ }^{17}$ showed that a cheap quaternary ammonium-salt can be successfully used as a solvent to extract the glycerol from palm oil-based biodiesel in a continuous separation process. In the pharmaceutical area Morrison et al. ${ }^{18}$ used ethylene glycol-based DES to increase the solubility of very low water solubility compounds favoring bioavailability in early drug development studies. Shekaari et al. ${ }^{11}$ studied the effect of using choline chloride/ethylene glycol, or glycerol, as co-solvents on the acetaminophen solubility enhancement, showing that interactions with acetaminophen became stronger by increasing the DES concentration. ${ }^{11}$ Additionally, polyalcohols and their eutectic mixtures have been proposed as potential phase change materials substitutes, ${ }^{19,20}$ which are an important class of modern materials that contribute to the efficient use and storage of energy in processes such as solar thermal, industrial waste heat recovery and thermal management of electronics.

When selecting eutectic systems, many authors tend to study only fixed stoichiometric mole ratios and report those at which the mixtures are visually liquid at room temperature. ${ }^{4,5,14}$ However, to select the appropriate molar ratio of the ES components, and the operating temperature for a specific application, the solid-liquid equilibria (SLE) phase diagrams must be known, ${ }^{8}$ but very seldom in studies on eutectic systems the SLE phase diagrams were characterized. Additionally, the physicochemical characterization of the resulting mixture is also poor. Among the studies available in the literature involving eutectic mixtures of $[\mathrm{Ch}] \mathrm{Cl}$ and polyalcohols, only Abbott and co-workers ${ }^{16}$ have measured the SLE phase diagram for the system $[\mathrm{Ch}] \mathrm{Cl}+$ glycerol. This was later complemented with an extensive study of the physicochemical properties of that system by the same group. ${ }^{14}$ It was shown it could be used effectively at room temperature, ${ }^{16}$ in spite of its high viscosity ${ }^{14}$ that could be a limitation to some applications of this solvent at an industrial scale.

The number of applications and the performance of these mixtures can be enhanced and optimized by an a priori knowledge on the phase equilibria and thermodynamic properties of these mixtures. In parallel, this knowledge also contributes to a more profound understanding 
of the type and magnitude of the interactions governing these mixtures that, subsequently, enables the development of theoretical models able to accurately correlate and predict the behavior of these mixtures under different conditions, avoiding a high number of experimental measurements.

In this work, eutectic binary mixtures of $[\mathrm{Ch}] \mathrm{Cl}$ with polyalcohols are investigated. The SLE phase diagrams of six $[\mathrm{Ch}] \mathrm{Cl}$ based-eutectic mixtures containing ethylene glycol, glycerol, 1,3propanediol, meso-erythritol, sorbitol, or xylitol were measured in the full composition range. The main goal is to provide meaningful information on the compositions and temperature ranges for operating these alternative solvents. Additionally, densities, viscosities, and solvatochromic parameters were determined for each system at the eutectic composition.

\section{Experimental Section}

\section{Chemicals}

The source, purity, and melting properties of the compounds studied in this work are detailed in Table 1, while their chemical structures are illustrated in Figure S1. The [Ch]Cl was dried under vacuum, at room temperature and at atmospheric pressure with constant stirring, for at least 72 hours. For ethylene glycol, 1,3-propanediol, and glycerol, a purification was done through contact with zeolites $(<45 \mu \mathrm{m})$ for 72 hours. All the remaining compounds were stored at room temperature and used as received from the supplier as they present a low hygroscopicity. The water content was measured using a Metrohm 831 Karl-Fischer coulometer, with the analyte Hydranal Coulomat AG from Riedel-de Haën and was found to be lower than $600 \mathrm{ppm}$ for choline chloride and below $150 \mathrm{ppm}$ for the remaining compounds.

Table 1. Source, purity (according to the supplier) and melting properties of the substances used in this work.

\begin{tabular}{ccccc}
\hline Compound & Supplier & Mass Purity $\%$ & $\boldsymbol{T}_{\boldsymbol{m}} / \mathbf{K}$ & $\boldsymbol{\Delta}_{\boldsymbol{m}} \boldsymbol{H} / \mathbf{k J} \cdot \mathbf{m o l}^{-\mathbf{1}}$ \\
\hline Choline chloride ([Ch]Cl) & Acros Organics & 98 & $597^{21}$ & $4.3^{21}$ \\
Ethylene glycol (EG) & Sigma-Aldrich & 99.5 & $256.6^{22}$ & $9.5^{22}$ \\
1,3-propanediol (PD) & Sigma-Aldrich & 99.5 & $249^{23}$ & $11.4^{23}$ \\
Glycerol (Gly) & Fischer Chemical & 99.88 & $293^{23}$ & $18.28^{23}$ \\
Meso-erythritol (ME) & Alfa Aesar & 99 & $391.2^{24}$ & $38.9^{24}$ \\
Xylitol (Xyl) & Acros Organics & 99 & $365.7^{25}$ & $37.4^{25}$ \\
Sorbitol (Sor) & Fischer Bioreagents & 98 & $366.5^{25}$ & $30.2^{25}$ \\
\hline
\end{tabular}




\section{Solid-Liquid Phase Diagrams Measurements}

Due to the hygroscopic character of some polyalcohols and $[\mathrm{Ch}] \mathrm{Cl}$, all mixtures were prepared inside a dry-argon glove box at room temperature using an analytical balance from Kern (ALS $220-4 \mathrm{~N}$ ) with an accuracy of $0.2 \mathrm{mg}$. After the first heating to mix the compounds and immediate crystallization, three experimental methods were applied depending on the physical state of the mixture. $i$ ) For mixtures presenting a pasty consistency, samples were heated in an oil bath under stirring until complete melting. The melting temperatures, measured using a Pt100 probe $( \pm 0.1 \mathrm{~K})$, correspond to the last solid disappearance. $i i)$ For mixtures showing complete recrystallization, the samples were ground in the glove box, and the powder was filled into a glass capillary. The melting point was then measured in a device model M-565 from Büchi, with a temperature resolution of $0.1 \mathrm{~K}$. Each procedure was repeated at least three times. iii) For mixtures liquid at room temperature, a Hitachi DSC7000X model working at atmospheric pressure was applied. Samples of approximately $2-5 \mathrm{mg}$ tightly sealed in aluminum pans were prepared inside the dry-argon glovebox and submitted to one repeated cooling-heating cycles at $5 \mathrm{~K} \mathrm{~min}^{-1}$ (cooling) and $2 \mathrm{~K} \mathrm{~min}^{-1}$ (heating). The thermal transition temperatures were taken as the peak temperature. The equipment was previously calibrated with several standards with weight fraction purities higher than $99 \%$.

\section{Preparation of Eutectic Mixtures}

To further characterize the eutectic systems, a certain number of compositions per system were selected (Table S1) and prepared in a larger quantity ( 2 batches of $5 \mathrm{~g}$ ), following the procedure described above. After melting and immediate cooling at room temperature, mixtures were stored for 2 days in the glove box to check their stability.

\section{Density and Viscosity Measurements}

Densities and viscosities were measured at atmospheric pressure in the temperature range from 278.15 to $373.15 \mathrm{~K}$ using an SVM 3001 Anton Paar viscometer-densimeter (temperature uncertainty: $\pm 0.03 \mathrm{~K}$; absolute density uncertainty: $1 \times 10^{-4} \mathrm{~g} \mathrm{~cm}^{-3}$, relative viscosity uncertainty: $0.35 \%$ ). Mixtures with compositions close to the eutectic point were used (Table S1). The water content of each mixture was measured using a Karl-Fischer coulometer (described above) and the results are presented in Table $\mathbf{S 2}$. 


\section{Kamlet-Taft Solvatochromic Parameters}

The Kamlet-Taft solvatochromic parameters, $\alpha, \beta$, and $\pi^{*}$ were measured at $298 \mathrm{~K}$ for $\alpha$ parameter and at $323.15 \mathrm{~K} \beta$ and $\pi^{*}$ parameters, in mixtures with compositions close to the eutectic point (Table S1). For the systems $[\mathrm{Ch}] \mathrm{Cl}+\mathrm{EG}$ and $[\mathrm{Ch}] \mathrm{Cl}+\mathrm{glycerol}$, the solvatochromic parameters were measured over the entire composition range in which the system is in a liquid state at $323.15 \mathrm{~K}$ (Table S1). The measurements of $\pi^{*}, \beta$, and $\alpha$ were performed by adding small amount of the probes $N, N$-diethyl-4-nitroaniline, 4-nitroaniline or pyridine- $N$-oxide, respectively, to the mixtures, that were immediately stirred at $323.15 \mathrm{~K}$ and $1400 \mathrm{rpm}$ using an Eppendorf Thermomixer Comfort until complete dissolution. Whereas $\alpha$ was obtained by ${ }^{13} \mathrm{C}$ nuclear magnetic resonance (NMR) spectra, using a Bruker Avance 300 apparatus at $75 \mathrm{MHz}, \pi^{*}$ and $\beta$ parameters were obtained using the longest wavelength absorption band determined by UV-Vis spectroscopy (BioTeck Synergy HT microplate reader) at $323.15 \mathrm{~K}$. Trimethylsilyl propanoic acid (TSP) and deuterium oxide $\left(\mathrm{D}_{2} \mathrm{O}\right)$ were respectively used as internal reference and solvent in the NMR measurements. The procedure was repeated at least three times for parameters $\pi^{*}$ and $\beta$. The equations used to calculate the parameters are available in SI.

\section{Soli-liquid equilibrium}

After some assumptions, the solubility of a solid solute in a liquid solvent, can be obtained from the following expression: ${ }^{26}$

$\ln \left(x_{i} \cdot \gamma_{i}\right)=\frac{\Delta_{m} H_{i}}{R} \cdot\left(\frac{1}{T_{m, i}}-\frac{1}{T}\right)+\frac{\Delta_{m} C p_{i}}{R} \cdot\left(\frac{T_{m, i}}{T}-\ln \frac{T_{m, i}}{T}-1\right)$

where $x_{i}$ is the mole fraction of the solute $i$ in the liquid phase, $\gamma_{i}$ its activity coefficient in the liquid phase, $\Delta_{m} H_{i}$ and $T_{m, i}$ its melting enthalpy and temperature, respectively, and $\Delta_{m} C p_{i}$ represents its heat capacity change upon melting, $R$ is the ideal gas constant, and $T$ is the absolute temperature of the system. The heat capacity change upon melting is often not known (e.g. $[\mathrm{Ch}] \mathrm{Cl}$ ), but its contribution to the second term of Equation 1 is typically negligible, ${ }^{27}$ allowing Equation 1 to be simplified as: ${ }^{28}$

$\ln \left(x_{i} \cdot \gamma_{i}\right)=\frac{\Delta_{m} H_{i}}{R} \cdot\left(\frac{1}{T_{m, i}}-\frac{1}{T}\right)$ 
Therefore, knowing the melting properties of the solute, using Equation 2 one can estimate the activity coefficients from the experimental data, allowing to evaluate the non-ideality of the liquid phase. Furthermore, the experimental solubilities can also be compared with those obtained assuming an ideal solution by setting the activity coefficients to unity.

\section{Results \& Discussion}

\section{$\underline{\text { Solid-liquid phase diagrams }}$}

The six SLE phase diagrams measured in this work are depicted in Figure 1, along with the ideal liquid phase curves and the experimental activity coefficients. The detailed experimental data and experimental activity coefficients are listed in Table S3 of Supporting Information. The experimental activity coefficients were calculated using Eq. (2), without considering the solid-solid transition of choline chloride. Other relevant thermic events as eutectic temperatures and solid-solid and glass transitions are reported in Table S4. In the eutectic region of $[\mathrm{Ch}] \mathrm{Cl}+$ glycerol it was not possible to measure the melting temperatures due to crystallization problems and in these cases, only the glass transitions were observed and reported. 

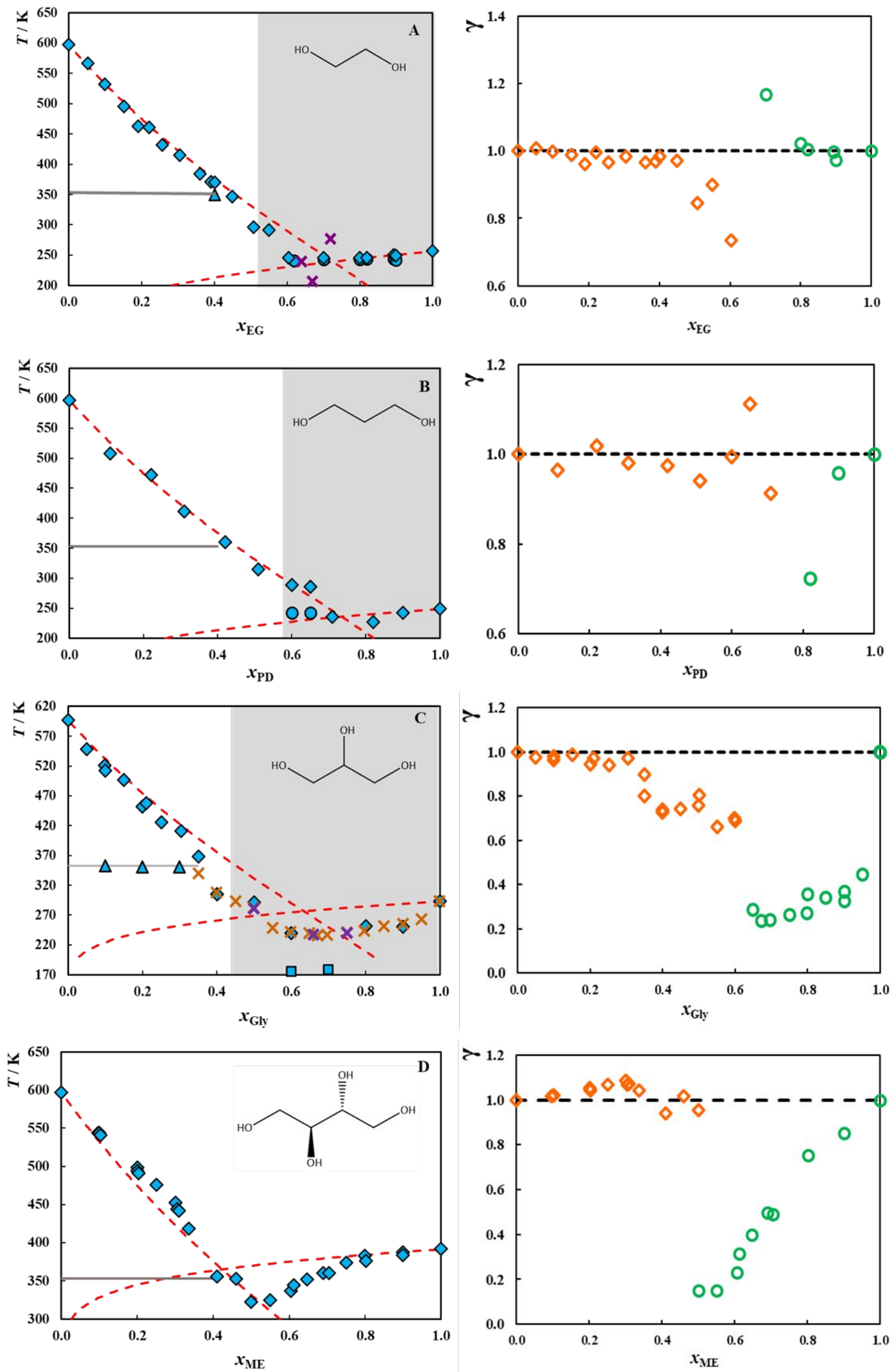

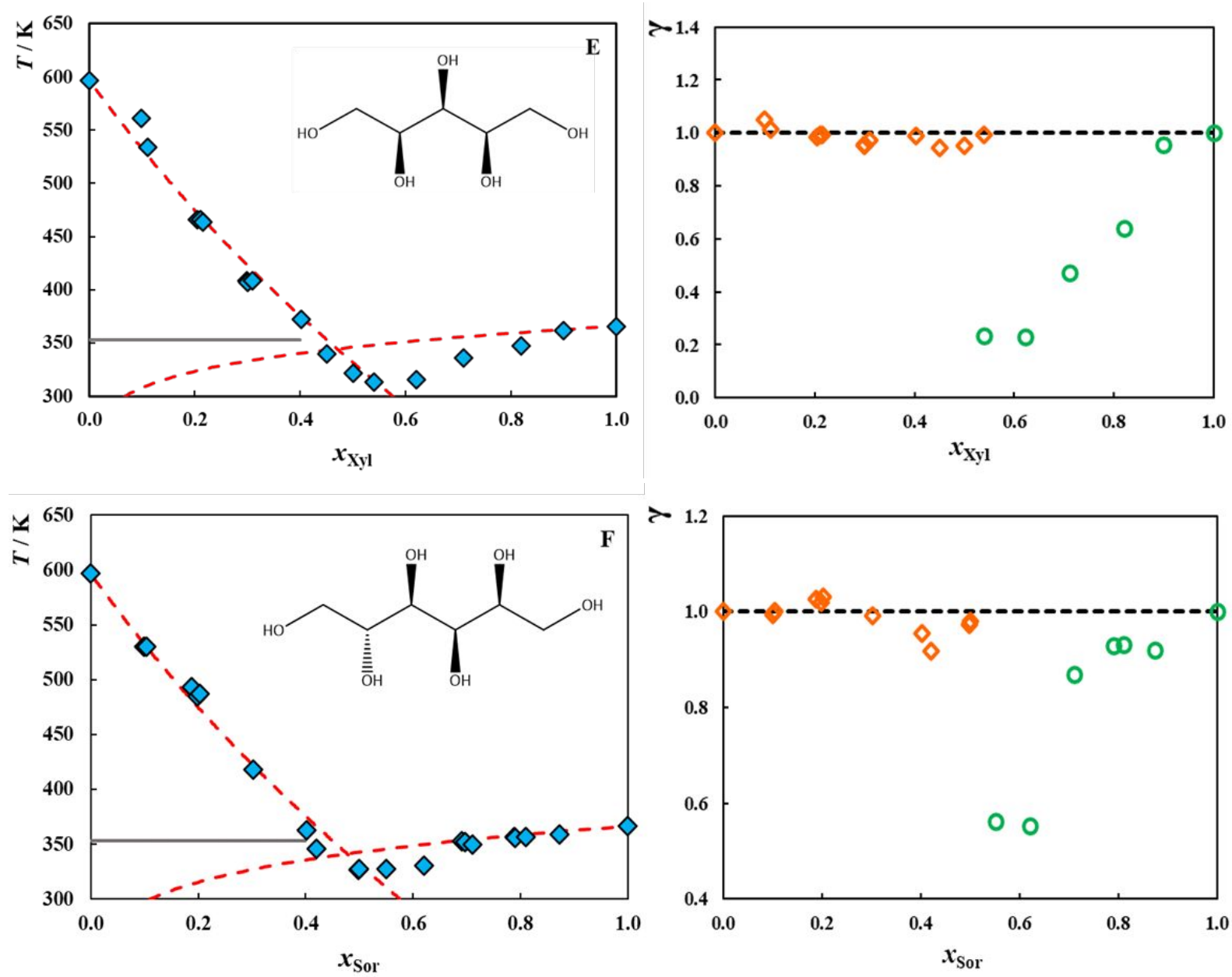

Figure 1. Solid-liquid phase diagrams (left) and activity coefficients (right) for binary mixtures composed of choline chloride and a polyalcohol: A) EG; B) PD; C) Gly; D) ME; E) Xyl and F) Sor. Legend: •, experimental melting temperatures measured in this work; " , glass transitions temperatures; $\odot$, eutectic temperatures; $\triangle,-,[\mathrm{Ch}] \mathrm{Cl}$ solid-solid transition $\left(T_{\mathrm{SS}}=\right.$ $\left.352.93 \mathrm{~K}, \Delta H_{\mathrm{SS}}=17.19 \mathrm{~kJ} \mathrm{~kJ} \cdot \mathrm{mol}^{-1}\right) ;{ }^{29}$ Literature: $\times$, Abbott et al. ${ }^{16} ; \times$, Bagh et al. ${ }^{30}$; - -, ideal solubility curve; $\diamond, \circ$, experimental activity coefficients, $---\gamma=1$. Gray regions represent the concentration range for which the mixture is liquid at room temperature ( $T=298.15 \mathrm{~K})$.

To the best of our knowledge, literature data is only available for $[\mathrm{Ch}] \mathrm{Cl}+$ glycerol and $[\mathrm{Ch}] \mathrm{Cl}$ + EG systems. For the system $[\mathrm{Ch}] \mathrm{Cl}+$ glycerol, Abbott et al. ${ }^{16}$ reported the freezing temperatures in a considerable composition range for $x_{\text {glycerol }}>0.3$, while Bagh et al. ${ }^{30}$ reported only 3 melting temperatures near the eutectic composition. Small discrepancies between both sets of data are observed - Figure 1C. For the system $[\mathrm{Ch}] \mathrm{Cl}+\mathrm{EG}$, there are discrepancies between our results and those reported in the literature by Bagh et $\mathrm{al}^{30}$ as can be seen in Figure 1A. $[\mathrm{Ch}] \mathrm{Cl}+\mathrm{EG}$ phase diagram was reported by us before, ${ }^{29}$ showing a considerable different SLE phase diagram than the one reported here for $x_{\mathrm{EG}}>0.4$, composition intersecting the solidsolid transition temperature of choline chloride (Figure S2). The discrepancies in the results 
obtained are attributed to the metastability of $[\mathrm{Ch}] \mathrm{Cl}$. The polymorphism of choline chloride was previously reported by Shanley and Collin ${ }^{31,32}$ that identified two forms: $\alpha$ and $\beta$, the latter observed for temperatures higher than the $[\mathrm{Ch}] \mathrm{Cl}$ solid-solid transition. This has an impact on the SLE phase diagram depending on choline chloride solid phase. Considering the temperature levels observed in both works, it indicates that here choline chloride remains in the $\alpha$ form, while in our previous work, it changes from $\alpha$ to $\beta$ at the SS transition temperature shifting the slope in the SLE phase diagram. The temperature and enthalpy for the solid-solid transition of $[\mathrm{Ch}] \mathrm{Cl}, 352.92 \mathrm{~K}$ and $17.19 \mathrm{~kJ} \cdot \mathrm{mol}^{-1}$, respectively, were measured in this work using DSC.

The high hygroscopicity of choline chloride can lead to a significant decrease in the melting temperature due to absorbed water. As shown by Meng et al., ${ }^{33}$ after 48 hours in contact with atmosphere samples containing [Ch]Cl can absorb $5.5 \mathrm{wt} \%$ of water leading to a decrease of more than $15{ }^{\circ} \mathrm{C}$ in the melting temperature. ${ }^{33}$ This result can contribute to explaining the discrepancies observed in the literature on the melting temperatures of different eutectic systems. ${ }^{33}$ However, in this work, the pure components were carefully dried (water content of $[\mathrm{Ch}] \mathrm{Cl}$ less than $600 \mathrm{ppm})$, and the preparation of all samples was made in a water-free environment $(<1 \mathrm{ppm})$, as described in the experimental section. Thus, it is improbable that the measured SLE phase diagrams here reported are significantly affected by the presence of undesired water.

As shown in Figure 1, all the studied systems exhibit a phase diagram characterized by a single eutectic point - as expected for systems where the constituents are immiscible in the solid phase. Additionally, the eutectic temperatures observed are much lower than those of pure $[\mathrm{Ch}] \mathrm{Cl}(597 \mathrm{~K})^{21}$ as common in other [Ch]Cl-based eutectic mixtures. ${ }^{8}$ On the other side, the lowering of the melting point of the polyalcohol is in general small for systems containing ethylene glycol $(-11.1 \mathrm{~K})$, propanediol $(-6.91 \mathrm{~K})$ and xylitol $(-18.8 \mathrm{~K})$ and large for glycerol ($57.64 \mathrm{~K})$, erythritol (-47.67 K) and sorbitol (-39.7 K).

Assuming an ideal behavior in the liquid phase $(\gamma=1)$, ideal solubility curves are also depicted in Figure 1, and evidence a quasi-ideal behavior in $[\mathrm{Ch}] \mathrm{Cl}$ solubility curve with activity coefficients close to 1 (Table S3) for all systems excepting for ethylene glycol and glycerol containing systems (Figures 1A and 1C) where some deviations to ideality are observed in the region below the solid-solid transition point.

Excepting the system $[\mathrm{Ch}] \mathrm{Cl}+\mathrm{EG}$, in the polyalcohol rich region all systems display negative deviations to ideality, indicating the existence of stronger interactions between $[\mathrm{Ch}] \mathrm{Cl}$ and the 
polyalcohol, than those observed in the pure polyalcohol. The non-ideality in the polyalcohol rich side seems to increase with the increasing number of hydroxyl groups and chain length till $[\mathrm{Ch}] \mathrm{Cl}+$ sorbitol, where the activity coefficients are close to one at high sorbitol mole fractions. Thus, the increase in the number of hydroxyl groups increases the possibility of crossinteractions with choline chloride favoring the non-ideality, to the extent where steric effects and strong interactions in the pure compound become dominant like in the case of sorbitol, leading to a significant deviation to the ideality.

The experimental eutectic point coordinates $\left(x^{E}\right.$ Polyol, $\left.T^{E}\right)$ are represented in Figure 2 and reported in Table S5, along with those calculated assuming an ideal behavior. The experimental eutectic points were determined from the interception between the two $\ln (x)$ vs 1/T curves (using Equation 2) and are plotted in Figure S3. Eq. (2) shows a linear relationship between $\ln (x)$ and 1/T and thus, a linear regression of a set of experimental data that can provide an indirect estimation of the experimental eutectic point for these systems. Due to the lack of experimental points observed for the system $[\mathrm{Ch}] \mathrm{Cl}+$ glycerol due to recrystallization difficulties in the eutectic region, and as the SLE phase diagram measured here is in agreement with the one reported by Abbot et al., ${ }^{16}$ the two experimental sets of data were used to calculate the experimental eutectic point for this system.

As can be seen in Figure 2, with the exception of the systems involving ethylene glycol and propanediol where $T_{\text {exp }}^{\mathrm{E}} \approx T_{\text {ideal, }}^{\mathrm{E}_{\text {, }}}$ the eutectic temperatures obtained in this work are lower than those predicted assuming an ideal solution, due to the negative deviations from ideality of these systems. Regarding the eutectic compositions, in almost all systems $x^{\mathrm{E}}$ exp $>x^{\mathrm{E}}$ ideal due to those negative deviations being present in the $\mathrm{HBD}$, the $[\mathrm{Ch}] \mathrm{Cl}$ showing a near ideal behavior as discussed above.

Both $x^{\mathrm{E}}$ exp and $T^{\mathrm{E}}$ exp depend strongly on the number of functional groups present in the polyol chemical structure. These can be divided into two groups: those that present up to $3 \mathrm{OH}$ groups - ethylene glycol, propanediol, and glycerol; and those having more than $3 \mathrm{OH}$ groups in their structure (erythritol, xylitol, sorbitol). In each group, the experimental eutectic coordinates are similar. This means that the eutectic coordinates are mainly controlled by the HBD chemical structure, specifically the number of functional groups and their interaction with the HBA. This can be seen in the eutectic temperature of the mixture $[\mathrm{Ch}] \mathrm{Cl}+$ erythritol that is lower than that observed for the system $[\mathrm{Ch}] \mathrm{Cl}+$ sorbitol, although the melting temperature of erythritol is 25 $\mathrm{K}$ higher than that of sorbitol. Although sorbitol has two more -OH group able to interact with 
$[\mathrm{Ch}] \mathrm{Cl}$ the intermolecular interactions between $[\mathrm{Ch}] \mathrm{Cl}$ and erythritol are stronger, as the activity coefficients suggest, and the temperature depression confirms, showing that the two additional - $\mathrm{OH}$ groups present in sorbitol do not contribute for stronger interactions with $[\mathrm{Ch}] \mathrm{Cl}$, but for more interactions with other sorbitol molecules. These results suggest that additional hydroxyl groups in the HBD, and their configuration on the chemical structure play an important role in the interactions with $[\mathrm{Ch}] \mathrm{Cl}$. This is in agreement with our previous work, ${ }^{34}$ where we investigated mixtures composed of $[\mathrm{Ch}] \mathrm{Cl}$ and sugars. In that work it was observed that the interactions with the chloride anion seem to be favored by some sugar configurations, as demonstrated by the difference in the values of the activity coefficient between the two isomers reported there, arabinose and xylose. ${ }^{34}$

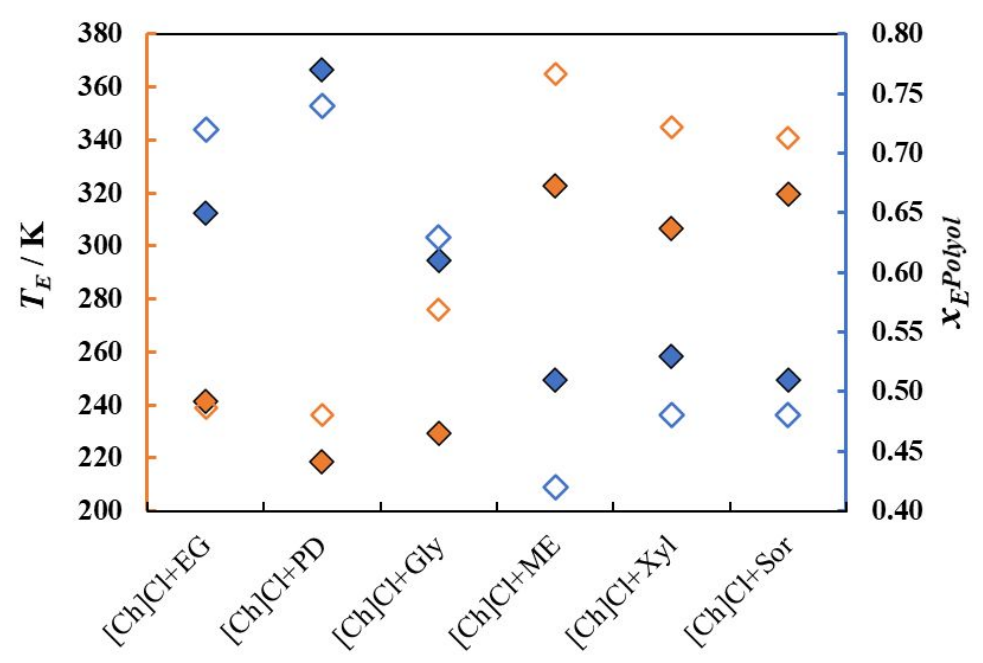

Figure 2. Eutectic coordinates for the systems measured in this work. Legend: $\diamond, \diamond$ Eutectic composition (polyol mole fraction) and $\downarrow, \diamond$ eutectic temperature. The full marks correspond to the experimental data, while the open marks are calculated assuming ideality. For the system $[\mathrm{Ch}] \mathrm{Cl}+$ glycerol the experimental coordinates were reported by Abbott et al. ${ }^{16}$

Although the systems studied are often reported as DES, ${ }^{4,5,12,13,16,35-38}$ it is here demonstrated that in some mixtures the eutectic temperature is very close to that predicted assuming ideality ([Ch]Cl+ethylene glycol or propanediol). The absence of favourable interactions on these systems is further supported by the excess enthalpy measurements reported by Lopez-Porfiri et al. ${ }^{37}$ showing these mixtures to be endothermic. Moreover, almost all systems studied present a quasi-ideal behavior in the $[\mathrm{Ch}] \mathrm{Cl}$ solubility curve. This means that the interactions between the components are not significantly different from those present in the pure compound to induce negative deviations from ideality and the temperature depressions associated with them. Nevertheless, systems composed of $[\mathrm{Ch}] \mathrm{Cl}$ and ethylene glycol, propanediol or glycerol, 
present a wide compositions range at which the mixtures are liquid at room temperature. One cannot help noticing that the formulation of liquid mixtures at room temperature with the compounds here studied only occurs when the HBD used is already liquid at room temperature (ethylene glycol, propanediol, or glycerol), and thus they should more appropriately be considered solutions of $[\mathrm{Ch}] \mathrm{Cl}$ on these solvents rather than DES.

\section{$\underline{\text { Densities and Viscosities }}$}

In general, a useful solvent should have a low viscosity allowing for fast mass transfer, and a density sufficiently different from water for good phase demixing. Therefore, these two physicochemical properties were studied to further characterize the mixtures herein investigated.

Densities of the polyalcohol-based mixtures at a composition near the eutectic point composition (see Table S1), were measured at atmospheric pressure in the temperature range from 278.15 to $373.15 \mathrm{~K}$, and are presented in Figure 3, and reported in the tabular form in Table S6.

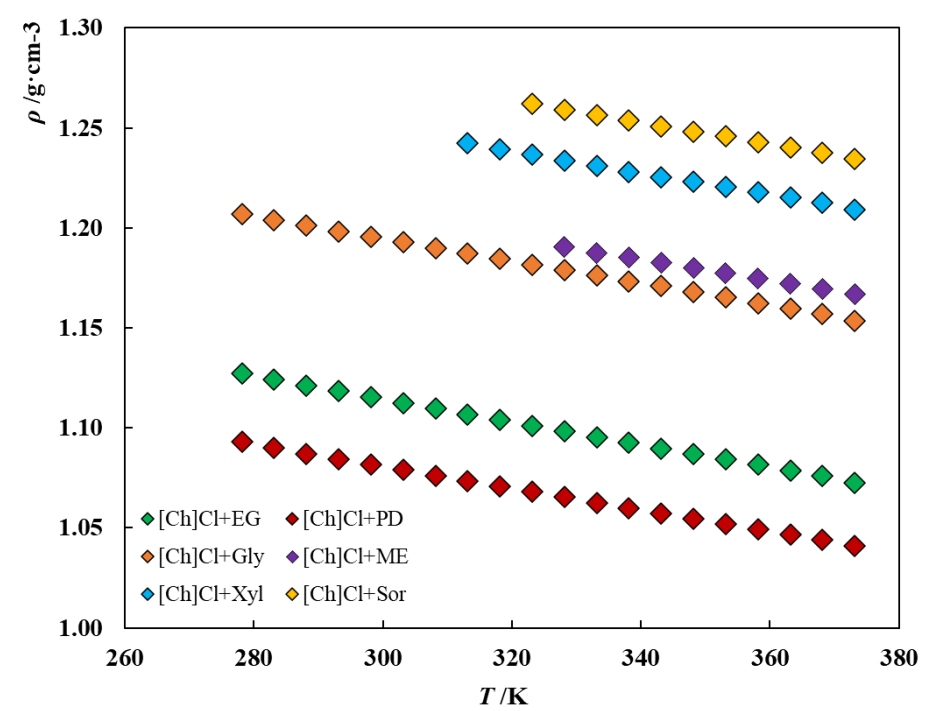

Figure 3. Density of the binary systems $[\mathrm{Ch}] \mathrm{Cl}(1)+$ polyalcohol(2) at different temperatures and a mole fraction of component 2 of: EG) 0.67; PD) 0.75; Gly) 0.68; ME) 0.50; Xyl) 0.55 and Sorb) 0.50 .

All systems present densities higher than water being $[\mathrm{Ch}] \mathrm{Cl}+$ propanediol and $[\mathrm{Ch}] \mathrm{Cl}+$ sorbitol mixtures the less and more denser, respectively. As expected, density decreases linearly with increasing temperature due to thermal expansion. Similarly to the density of pure polyalcohols, at a fixed temperature, density increases with the increase of the alkyl chain length and the 
number of -OH group in the polyalcohol structure. ${ }^{39}$ Ethylene glycol and 1,3-propanediol both

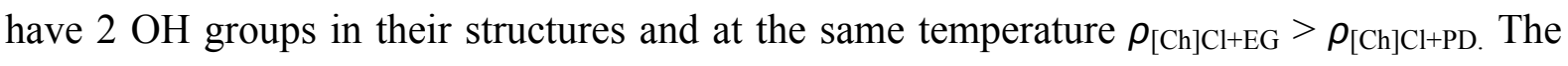
organic salt/HBD molar ratio also has a strong effect on the densities of ES. Analyzing the mole fraction of choline chloride in each mixture, one can say that density increases with the amount of $[\mathrm{Ch}] \mathrm{Cl}$ in the mixture for systems involving ethylene glycol, propanediol and glycerol, as can be seen comparing the systems $[\mathrm{Ch}] \mathrm{Cl}+$ propanediol with $x_{[\mathrm{Ch}] \mathrm{Cl}} \approx 0.25$, and system $[\mathrm{Ch}] \mathrm{Cl}+\mathrm{EG}$ with $x_{[\mathrm{Ch}] \mathrm{Cl}} \approx 0.33$, where the amount of $[\mathrm{Ch}] \mathrm{Cl}$ influences the density of the mixtures. The remaining systems, all have approximately the same mole fraction of choline chloride, $x_{[\mathrm{Ch}] \mathrm{Cl}} \approx 0.5$.

Differences in density can be explained in terms of the molecular arrangement or packing of the ES. This was previously analyzed by Garcia et al., ${ }^{36}$ who reported that the molecular characteristics of the HBD and the molar ratio at which the ES is formed have a large effect on their density and its temperature variation. In this work, the system $[\mathrm{Ch}] \mathrm{Cl}+$ sorbitol is denser due to the higher intermolecular packing of the mixture structure. The volume packing indicates that systems with larger molecules of polyalcohol, or that present more functional groups in their structure, are arranged in a more packed arrangement than systems containing smaller polyalcohol molecules. Also, bigger polyalcohols are able to occupy a part of the space between the polar heads of the $[\mathrm{Ch}] \mathrm{Cl}$ cation and anion which cannot be occupied by the pure compounds or small species. ${ }^{36}$

The experimental density data measured in this work is plotted against literature data for the same systems at the same composition (1:2, HBA:HBD) and the respectively pure polyalcohol density (Figure S4). The percentage average relative deviations, $\% A R D$, were calculated through:

$$
\% A R D(X)=100\left|\frac{X^{l i t}-X^{\exp }}{X^{\exp }}\right|
$$

where $X^{l i t}$ and $X^{\exp }$ are the literature and the experimental quantities, respectively.

A good agreement between the data reported in this work and those reported in the literature for $[\mathrm{Ch}] \mathrm{Cl}+\mathrm{EG}$ and $[\mathrm{Ch}] \mathrm{Cl}+\mathrm{glycerol}$ is observed, with an $\% A R D$ in the range of $0.3 \%$. Overall, small and non-systematic deviations were found between the different sets of data. An exception is the density reported by Leron et al. ${ }^{40}$ for the mixtures with glycerol, and for 
temperatures above $320 \mathrm{~K}$, where the density values reported are significantly lower than those measured in this work. Differences may be attributed to the presence of water on their samples.

Comparing the density between the mixtures, and the corresponding pure polyalcohol, one can realize that for ethylene glycol and propanediol, the densities of the mixtures are higher than those reported to the pure compounds. ${ }^{22}$ Like ionic liquids, in ES a lattice containing holes or empty vacancies is structured in the solution. It seems that when ethylene glycol or propanediol are mixed with $[\mathrm{Ch}] \mathrm{Cl}$, the average hole radius is decreased ${ }^{41}$ resulting in a slight increase of the ES density as compared to that of the pure solvent. ${ }^{16}$ On the contrary, the ES containing glycerol presents a smaller density than reported for the respective pure polyalcohol. ${ }^{22}$ These differences can be associated with the free volume in the system and the number of -OH groups in the polyalcohol structure, since ethylene glycol and propanediol both have one $\mathrm{OH}$ group less than glycerol. ${ }^{13,35}$

Viscosities of the same polyalcohol-based mixtures (compositions at Table S1) were measured at atmospheric pressure, in the temperature range from 278.15 to $373.15 \mathrm{~K}$, and are presented in Figure 4 and, and reported in the tabular form in Table S7.

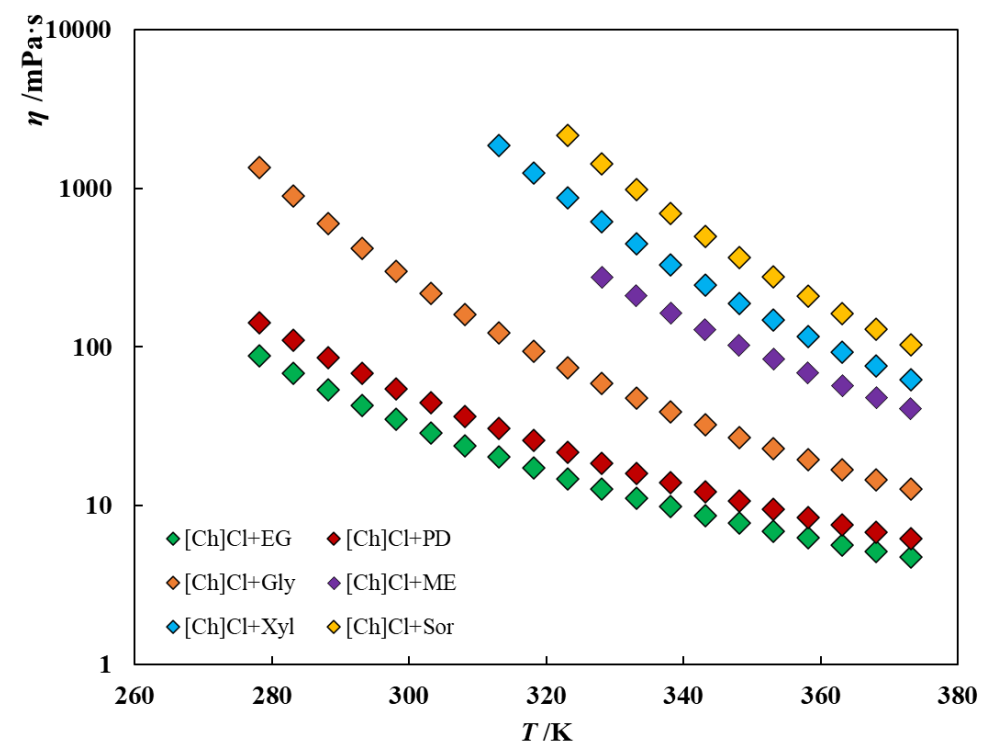

Figure 4. Viscosity of the binary systems $[\mathrm{Ch}] \mathrm{Cl}(1)+$ polyalcohol(2) at different temperatures and a mole fraction of component 2 of: EG) 0.67; PD) 0.75; Gly) 0.68; ME) 0.50; Xyl) 0.55 and Sorb) 0.50 .

The viscosities of the investigated systems are higher than water and decrease with increasing temperature. Moreover, the number and position of the functional groups strongly influence the behavior of these systems as, at a fixed temperature, viscosity increases with the number of 
-OH groups and number of carbons in the polyalcohol structure, as for pure polyalcohols. For instance, $[\mathrm{Ch}] \mathrm{Cl}+\mathrm{EG}$ exhibits a viscosity of $34.96 \mathrm{mPa}$ s at $298 \mathrm{~K}$, much lower than the viscosity of $[\mathrm{Ch}] \mathrm{Cl}$ combined with glycerol in the same proportion and at the same temperature $(298.57 \mathrm{mPa} \cdot \mathrm{s}$ at $298 \mathrm{~K})$. The higher viscosity of the later is due to the presence of a more robust 3D intermolecular hydrogen-bond network, increasing the viscosity of the system. The highest viscosity is observed for $[\mathrm{Ch}] \mathrm{Cl}+$ sorbitol, where sorbitol has more $-\mathrm{OH}$ groups than the other polyalcohols, forming more extensive H-bonds networks in the mixture. The activity coefficients of the mixtures can support this evidence. Smaller activity coefficients indicate greater molecular interactions between the species. Thus, mixtures comprising polyalcohol's with less -OH groups, like EG, have greater activity coefficient in the eutectic point than mixtures with a higher number of $-\mathrm{OH}$ groups, leading to lower viscosities, due to the less robust intermolecular hydrogen-bond network. It was previously reported that increasing alkyl chain length or the number of functional groups causes an increase in van der Waals interactions and hydrogen bonds, which results in lower mobility of free species within the ESs, making them more viscous. ${ }^{13,35,42}$ However, the effect of chain length is less relevant at higher temperatures where viscosity values are closer among the various series ${ }^{43}$ Regarding the mole fraction of choline chloride in each system, its increase seems to lead to an increase in the viscosity values.

Although several authors reported viscosity data for the mixture of choline chloride with $\mathrm{EG}^{44-}$ 46 and glycerol ${ }^{44,46,47}$, to the best of our knowledge, no data were reported for the remaining ES investigated. A comparison of the available literature data with the values measured in this work for $[\mathrm{Ch}] \mathrm{Cl}+\mathrm{EG}$ or glycerol, at the same molar proportion (1:2, HBA:HBD), is plotted in Figure S5 together with the viscosities of the pure polyalcohols ethylene glycol, glycerol or propanediol, showing considerable viscosity deviations between the different literature sources, and with the data measured in this work, which can reach $90 \%$. These differences may arise from the experimental methodology used, sample preparation procedures, water content, or even impurities. It has been already reported that the sample preparation substantially influences the physicochemical properties of the ES. Florindo et al. ${ }^{48}$ reported differences of $6.5 \%$ between the viscosity data of DES samples prepared by the traditional heating and stirring method in comparison with a grinding approach. Although this effect is more significant for viscosity than density, it should be considered in both properties. As in density, the viscosity of mixtures of $[\mathrm{Ch}] \mathrm{Cl}$ with ethylene glycol and propanediol are higher than the pure corresponding polyalcohol, while the mixture with glycerol presents a lower viscosity than the 
pure HBD. Glycerol has strong cohesive energy due to the presence of an extensive intermolecular hydrogen bond network. This drastic decrease of the viscosity upon the addition of $[\mathrm{Ch}] \mathrm{Cl}$ in the mixture was attributed to the partial rupture of the hydrogen bond network of glycerol, which can be corroborated by analyzing the low activity coefficients of glycerol in this mixture (close to 0.24 ) that reinforces the strong interaction between $[\mathrm{Ch}] \mathrm{Cl}$ and glycerol. ${ }^{14}$

The experimental viscosity data of the systems $[\mathrm{Ch}] \mathrm{Cl}+$ glycerol or ethylene glycol was further compared with literature data involving different ${ }^{49-51}$ HBAs and at the same HBD/HBA molar ratio - Figure S6. The systems studied in this work have lower viscosities than the other ammonium, or phosponium based ES. Within the ammonium group, and at the same temperature, it was observed that the viscosities of the different ES increase as the HBA molecular volume increases $([\mathrm{Ch}] \mathrm{Cl}<\mathrm{DAC}<\mathrm{TEMA}<\mathrm{BTMA}<\mathrm{TBAB})$. Additionally, the salts that have aromatic rings in their structure (like MTPB, BTPC, and BTMA) lead to ES with higher viscosities. These results show that ES are tunable solvents with viscosities that can be designed considering the structure of both the HBA and HBD.

The viscosities of the studies ES are much larger than those of conventional liquid solvents, which can be explained by a large ion-to-hole radius ration in these eutectic mixtures, since ES are composed of roles holes or empty vacancies as reported by Abbott. ${ }^{13,41}$ One possibility to reduce their viscosities, and their densities, is the addition of water. As shown before by us, in systems with $[\mathrm{Ch}] \mathrm{Cl}+$ sugars and hydrophobic terpene+terpene mixtures, and others $\left[{ }^{33,52-54}\right]$ the addition of water, can reduce by approximately half the viscosities of these systems. ${ }^{34,55}$ However, this should be done with caution since it may affect and change other properties of the system.

The low toxicity and ready availability of the investigated polyalcohols make them very interesting solvents. However, their properties, namely high viscosities and densities, limits their use. The results reported in this work show that the addition of salt can be used to tune the ES properties, leading to higher or lower densities and viscosities, depending on the molar proportion of the mixture and the interaction between the components. The temperature has a significant effect on viscosity, and if highly viscous mixtures are formed at room temperature, which hampers its use for practical purposes, higher temperatures can be chosen instead. the meso-erythritol, xylitol, and sorbitol melt, or decompose upon melting, at temperatures around $373.15 \mathrm{~K}$ and thus, comparisons between their pure densities and viscosities with the ones measured in this work in mixtures with choline chloride are not possible. 


\section{$\underline{\text { Solvatochromic parameters }}$}

The solvatochromic parameters give information about the dipolarity/polarizability $\left(\pi^{*}\right)$, hydrogen bond donor $(\alpha)$ and acceptor $(\beta)$ capacities of a compound, or mixture, thereby providing insights into the solvent nature. Here, the Kamlet-Taft solvatochromic parameters of the $[\mathrm{Ch}] \mathrm{Cl}$-polyalcohol systems were measured at the same compositions (Table S1), and at $323.15 \mathrm{~K}$ for both $\pi^{*}$ and $\beta$, while $\alpha$ was measured at $298.15 \mathrm{~K}$. The experimental data are presented in Figures 5 and 6, and Table S8 (a brief description of the equations used is also available in SI). The parameters in the system $[\mathrm{Ch}] \mathrm{Cl}+$ erythritol were not measured due to the fast crystallization of the eutectic mixture. This does not happen in all other systems due to supercooling, allowing the measurement of the KT parameters at a temperature lower to their melting points. At these temperatures, only pure ethylene glycol, glycerol and propanediol are in the liquid state, and thus only for those pure polyalcohols the KT parameters were found: ethylene glycol $\beta=0.554, \alpha=1.05, \pi^{*}=0.956$; glycerol $\beta=0.480, \alpha=1.14, \pi^{*}=1.089$; and propanediol $\beta=0.602, \alpha=0.96, \pi^{*}=0.913$.

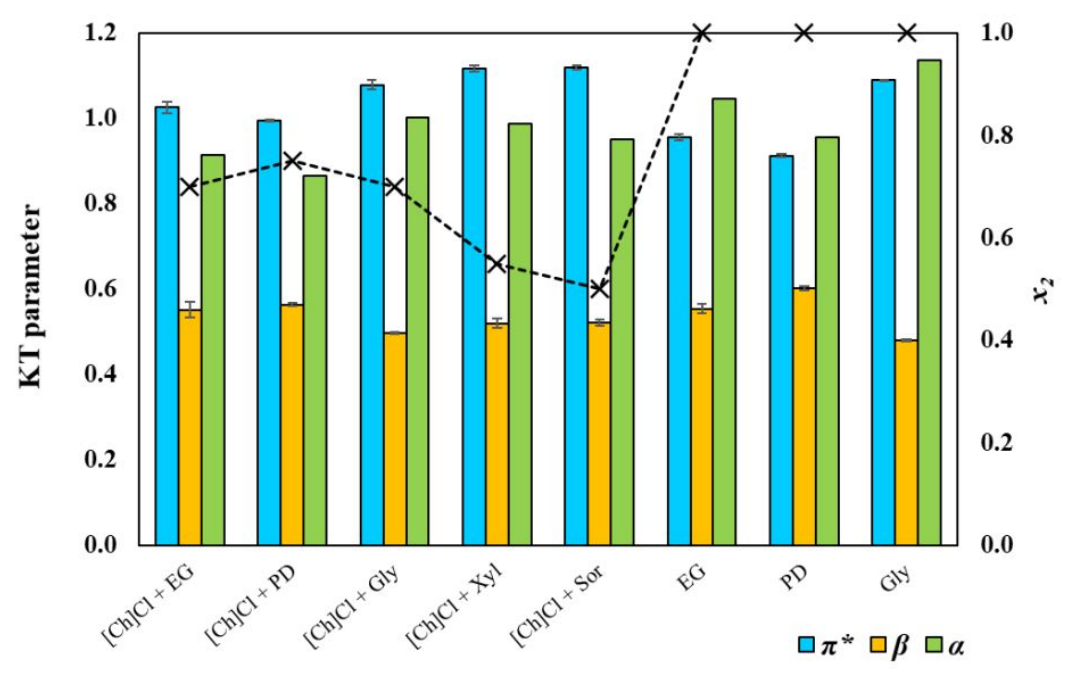

Figure 5. Kamlet-Taft solvatochromic parameter of some pure polyols and polyol $+\mathrm{ChCl}$ mixtures at compositions close to the eutectic point at $323.15 \mathrm{~K}\left(\pi^{*}\right.$ and $\beta$ ) or $298.15 \mathrm{~K}(\alpha)$. Clustered columns correspond to the KT parameters (left y-axis). The dotted line corresponds to the mole fraction of each polyalcohol in the respective mixture (righ y-axis).

The parameter $\pi^{*}$ provides a measure of the solvent polarizability/dipolarity and present values between $0.995([\mathrm{Ch}] \mathrm{Cl}+$ propanediol $)$ and $1.119([\mathrm{Ch}] \mathrm{Cl}+$ sorbitolb), considerably higher than those of conventional organic solvents (Table S8), and very close to water. Moreover, there is a slight increase in the $\pi^{*}$ value with the number of -OH groups in the alkyl chain length of the polyalcohol, which is probably connected to the simultaneous increase in the $[\mathrm{Ch}] \mathrm{Cl}$ mole 
fraction at the eutectic point. The parameter $\pi^{*}$ for the mixture studied in this work is always higher than the respective pure polyalcohol, except for glycerol containing system.

The $\beta$ and $\alpha$ parameters describe the hydrogen bond acceptor and donor capacity, respectively. The $\beta$ values obtained here for the mixtures are between $0.497([\mathrm{Ch}] \mathrm{Cl}+\mathrm{glycerol})$ and 0.563 ([Ch]Cl+propanediol), similar to methanol and acetone (Table S8), but smaller than the $\beta$ of ethanol. On the other hand, the $\alpha$ values are between $0.87([\mathrm{Ch}] \mathrm{Cl}+$ propanediol) and 1.12 $([\mathrm{Ch}] \mathrm{Cl}+\mathrm{glycerol})$, higher than most of the organic solvents used nowadays, but lower than water (Table S8). The variation observed for parameter $\beta$ is the opposite of $\alpha$, as previously reported. ${ }^{43}$ Mixtures involving polyalcohols with $2-\mathrm{OH}$ groups in their structures (EG and propanediol) present a higher capacity to accept hydrogen bonds (higher $\beta$ ) than mixtures involving other polyalcohols. Additionally, this parameter tends to increase with the polyalcohol mole fraction. The ability to act as hydrogen bond donor $(\alpha)$ is higher in mixtures involving polyalcohols with more than $2-\mathrm{OH}$ groups (glycerol, xylitol, and sorbitol). The values obtained for mixtures are lower than pure compounds in the case of the $\alpha$ parameter, while, in the case of $\beta$, the values are close to the corresponding pure polyalcohol. In general, mixtures with smaller polyalcohols, present a higher capacity to accept hydrogen bonds meaning a higher ability to establish nonspecific interactions with a solute, while the capacity to act as hydrogen bond donor is higher in mixture with higher polyalcohols.

Aiming to explore the designer solvent character of these mixtures, the KT solvatochromic parameters of $[\mathrm{Ch}] \mathrm{Cl}+\mathrm{EG}$ and $[\mathrm{Ch}] \mathrm{Cl}+$ glycerol were measured as a function of the polyalcohol mole fraction - Figure 6. For the system with ethylene glycol, $\pi^{*}$ decreases with the increase of ethylene glycol mole fraction, while $\beta$ shows a smooth minimum at around 0.80 of polyalcohol. In the case of $[\mathrm{Ch}] \mathrm{Cl}+$ glycerol system, $\pi^{*}$ increases with the increase of polyalcohol in the mixture. $\beta$ shows the opposite behavior. In both systems, parameter $\alpha$ increases with the increase of polyalcohol mole fraction. These results suggest that the desired properties of the final solvent can be tailored based on the mole fraction of the constituents avoiding the typical use of fixed stoichiometric proportions. 

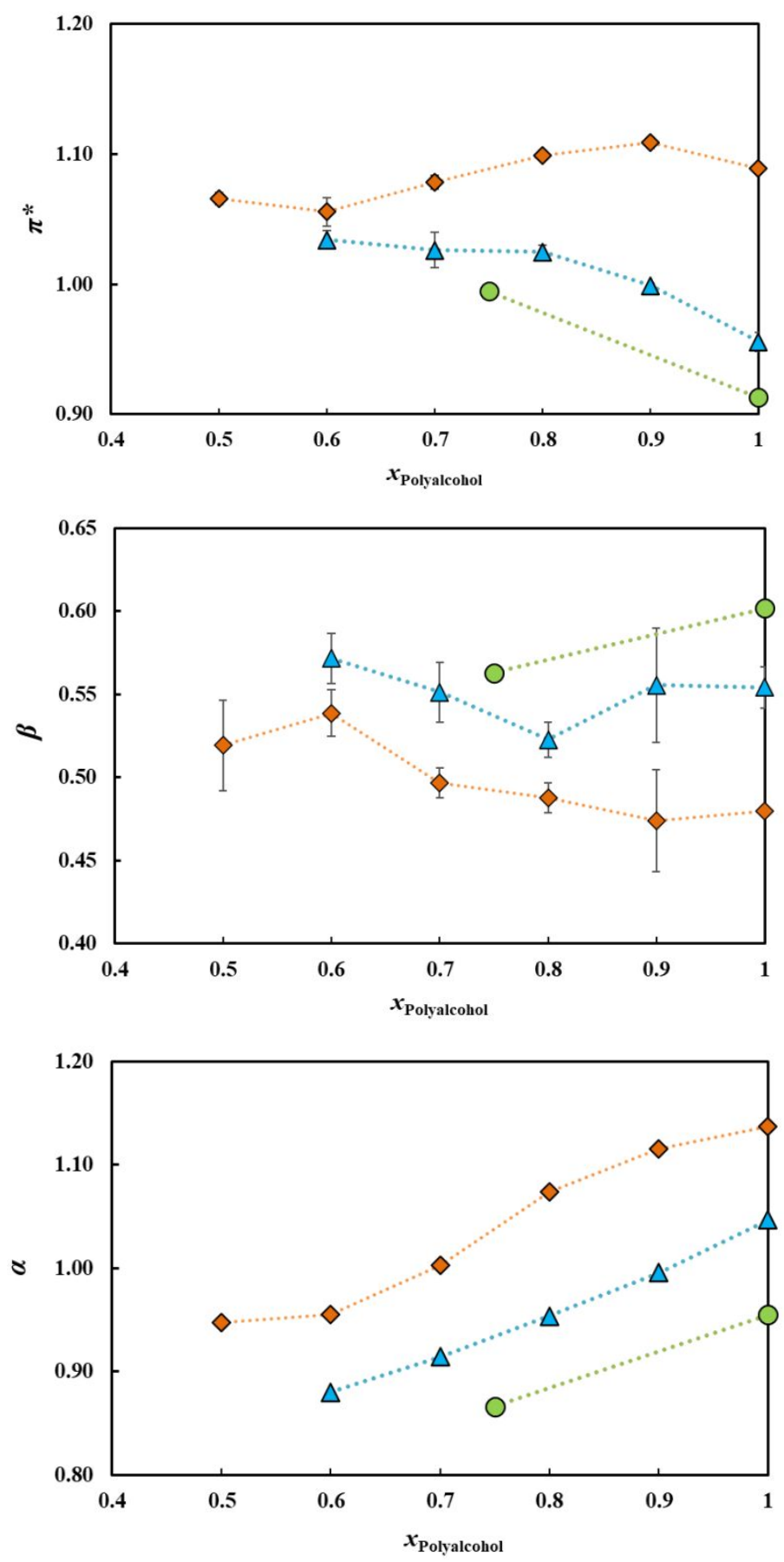

Figure 6. KT solvatochromic parameters of mixtures $[\mathrm{Ch}] \mathrm{Cl}+\mathrm{EG}$ and $[\mathrm{Ch}] \mathrm{Cl}+$ glycerol at $323.15 \mathrm{~K}\left(\pi^{*}\right.$ and $\left.\beta\right)$ and $298.15 \mathrm{~K}(\alpha)$ as a function of the polyalcohol mole fraction. The dotted lines are guides for the eyes. Legend: $\diamond[\mathrm{Ch}] \mathrm{Cl}+$ glycerol; $\Delta[\mathrm{Ch}]+\mathrm{EG} ; \bullet[\mathrm{Ch}] \mathrm{Cl}+$ propanediol.

In literature, some authors reported the KT solvatochromic parameters for $[\mathrm{Ch}]+\mathrm{EG}$ and $[\mathrm{Ch}]+$ glycerol systems and the pure compounds (see Table S9). In general, significant discrepancies between the different sets, especially for parameter $\pi^{*}$ can be observed being the results from literature larger than those here measured. However, it is important to highlight that the measurements were carried out at different compositions, inhibiting a direct 
comparison. Regarding the pure compounds, there are also some discrepancies in the KT values, namely for glycerol, and generally the results from literature lower than those here presented. Discrepancies can be attributed to the different probes used, different methodologies, water content and temperature. ${ }^{55-57}$

The studied mixtures present KT parameters similar to [Ch]Cl-based DES, but higher than those obtained for tetraalkylammonium-based DES, ${ }^{58,59}$ indicating that choline chloride plays an important role in the polarizability of these mixtures. The results obtained here have lower values than those of $[\mathrm{Ch}] \mathrm{Cl}+$ sugars previously reported by $\mathrm{us}^{47}$ for all parameters evaluated, probably due to the presence of a ring-shaped structure in sugars. ${ }^{43}$ Compared with hydrophobic mixtures containing only terpenes, or terpenes and fatty acids, the mixtures studied in this work present much higher values, except the $\pi^{*}$ parameter. ${ }^{43,55}$ These are related to the fact that cholinium based DES are constituted by charged moieties with polar groups, more polar than the terpenes-based mixtures formed by non-charged compounds.

\section{Conclusion}

Herein mixtures involving natural compounds - polyalcohols and choline chloride - were investigated, aiming to characterize their behavior and evaluate their potential as eutectic solvents. The SLE phase diagrams of the mixtures were measured in the full composition range using three different techniques. It is shown that in general choline chloride displays an ideal behavior while the polyalcohol exhibit negative deviations from ideality, resulting in a temperature depression that may lead to the formation of liquids at relatively low temperature. Results suggest that the number and positions of functional groups, HBD:HBA eutectic ratio and interactions in the pure HBD have a strong influence on the solubility of the HBD in the ES and thus on the eutectic melting temperatures.

Although these systems are often reported as DES, this works shows that this is somewhat arbitrary: negative deviations from ideality are only observed in one side of the SLE phase diagram and in some cases, small temperature depressions face to the pure polyalcohol are found, along with eutectic points very close to the ideally predicted ones. It must, however, be stressed that room temperature solvents can be obtained for some of these mixtures on a wide composition range and not fixed to any particular stoichiometric relationship between the hydrogen bond donor and acceptor, what reinforces the tunable character of the liquid phase region of these mixtures. 
The densities and viscosities were measured in order to evaluate the potential of these systems as solvents, and were found to be higher than water. Generally, both properties increase with the increase of -OH groups, and the number of carbons in the polyalcohol structure, as well as with the increase of $[\mathrm{Ch}] \mathrm{Cl}$ mole fraction in the eutectic mixture.

The mixtures investigated were further characterized measuring their solvatochromic parameters, which are influenced by the number of -OH groups in the polyalcohol structure, and vary with its mole fraction in the mixture. Mixtures involving ethylene glycol and propanediol present a higher hydrogen-bond basicity character, while mixtures involving polyalcohols with more than $2-\mathrm{OH}$ groups in their structure show a higher hydrogen-bond acidity and higher nonspecific interactions. Moreover, it was shown that mixture properties can be tailored changing the mole proportion of its constituents. The knowledge gathered here is a contribution for the study of eutectic mixtures involving choline chloride and polyalcohols, and their interactions, enhancing their attractiveness for pratical applications.

\section{Supporting Information}

Supporting information is available free of charge on the ACS Publications website. Water content of mixtures used in the density and viscosity measurements; experimental solid-liquid phase diagrams and calculated activity coefficients; experimental and ideal eutectic points; densities; viscosities; Kamlet-Taft solvatochromic parameters equations and experimental and literature values.

\section{Acknowledgments}

This work was developed within the scope of the project CICECO-Aveiro Institute of Materials, UIDB/50011/2020 \& UIDP/50011/2020, and CIMO-Mountain Research Center, UIDB/00690/2020, both financed by national funds through the Portuguese Foundation for Science and Technology/MCTES. The NMR spectrometers are part of the National NMR Network (PTNMR) and are partially supported by Infrastructure Project No 022161 (cofinanced by FEDER through COMPETE 2020, POCI and PORL and FCT through PIDDAC). L.P.S. acknowledges FCT for her PhD grant (SFRH/BD/135976/2018).

\section{References}

(1) Clarke, C. J.; Tu, W. C.; Levers, O.; Bröhl, A.; Hallett, J. P. Green and Sustainable 
Solvents in Chemical Processes. Chem. Rev. 2018, 118, 747-800.

https://doi.org/10.1021/acs.chemrev.7b00571.

(2) Zhao, H.; Xia, S.; Ma, P. Use of Ionic Liquids as "green" Solvents for Extractions. $J$.

Chem. Technol. Biotechnol. 2005, 80, 1089-1096. https://doi.org/10.1002/jctb.1333.

(3) Chemat, F.; Vian, M. A.; Ravi, H. K.; Khadhraoui, B.; Hilali, S.; Perino, S.; Tixier, A.

S. F. Review of Alternative Solvents for Green Extraction of Food and Natural

Products: Panorama, Principles, Applications and Prospects. Molecules 2019, 24, $1-$

26. https://doi.org/10.3390/molecules24163007.

(4) Dai, Y.; van Spronsen, J.; Witkamp, G. J.; Verpoorte, R.; Choi, Y. H. Natural Deep

Eutectic Solvents as New Potential Media for Green Technology. Anal. Chim. Acta

2013, 766, 61-68. https://doi.org/10.1016/j.aca.2012.12.019.

(5) Paiva, A.; Craveiro, R.; Aroso, I.; Martins, M.; Reis, R. L.; Duarte, A. R. C. Natural Deep Eutectic Solvents - Solvents for the 21st Century. ACS Sustain. Chem. Eng.

2014, 2, 1063-1071. https://doi.org/10.1021/sc500096j.

(6) Abbott, A. P.; Boothby, D.; Capper, G.; Davies, D. L.; Rasheed, R. K. Deep Eutectic Solvents Formed between Choline Chloride and Carboxylic Acids: Versatile

Alternatives to Ionic Liquids. J. Am. Chem. Soc. 2004, 126, 9142-9147.

https://doi.org/10.1021/ja048266j.

(7) Faggian, M.; Sut, S.; Perissutti, B.; Baldan, V.; Grabnar, I.; Acqua, S. D. Natural Deep Eutectic Solvents ( NADES ) as a Tool for Bioavailability Improvement :

Pharmacokinetics of Rutin Dissolved in Proline / Glycine after Oral Administration in

Rats : Possible Application in Nutraceuticals. Molecules 2016, 21, 1-11.

https://doi.org/10.3390/molecules21111531.

(8) Martins, M. A. R.; Pinho, S. P.; Coutinho, J. A. P. Insights into the Nature of Eutectic and Deep Eutectic Mixtures. J. Solution Chem. 2018, 48, 962-968.

https://doi.org/10.1007/s10953-018-0793-1.

(9) Wang, H.; Liu, S.; Zhao, Y.; Wang, J.; Yu, Z. Insights into the Hydrogen Bond Interactions in Deep Eutectic Solvents Composed of Choline Chloride and Polyols. ACS Sustain. Chem. Eng. 2019, 7 (8), 7760-7767.

https://doi.org/10.1021/acssuschemeng.8b06676.

(10) Chen, J.; Li, S.; Yao, Z.; Yang, D.; Zhang, L. Improved Stability of Salvianolic Acid B 
from Radix Salviae Miltiorrhizae in Deep Eutectic Solvents. Anal. Methods 2016, 8 (11), 2502-2509. https://doi.org/10.1039/C5AY03351A.

(11) Shekaari, H.; Zafarani-Moattar, M. T.; Shayanfar, A.; Mokhtarpour, M. Effect of Choline Chloride/Ethylene Glycol or Glycerol as Deep Eutectic Solvents on the Solubility and Thermodynamic Properties of Acetaminophen. J. Mol. Liq. 2018, 249, 1222-1235. https://doi.org/10.1016/j.molliq.2017.11.057.

(12) Manurung, R.; Simanjuntak, G. C.; Perez, R. N.; Syahputra, A.; Alhamdi, M. A.; Siregar, H.; Syahputri Zuhri, R. R. Production of Choline Chloride-Based Deep Eutectic Solvent with Hydrogen Bond Donor D-Glucose and Ethylene Glycol. IOP Conf. Ser. Mater. Sci. Eng. 2019, 505, 1-20. https://doi.org/10.1088/1757899X/505/1/012134.

(13) Troter, D. Z.; Todorović, Z. B.; Đokić-Stojanović, D. R.; Đordević, B. S.; Todorović, V. M.; Konstantinović, S. S.; Veljković, V. B. The Physicochemical and Thermodynamic Properties of the Choline Chloride-Based Deep Eutectic Solvents. $J$. Serbian Chem. Soc. 2017, 82, 1039-1052. https://doi.org/10.2298/JSC170225065T.

(14) Abbott, A. P.; Harris, R. C.; Ryder, K. S.; D’Agostino, C.; Gladden, L. F.; Mantle, M. D. Glycerol Eutectics as Sustainable Solvent Systems. Green Chem. 2011, 13, 82-90. https://doi.org/10.1039/c0gc00395f.

(15) Oliveira, F. S.; Pereiro, A. B.; Rebelo, L. P. N.; Marrucho, I. M. Deep Eutectic Solvents as Extraction Media for Azeotropic Mixtures. Green Chem. 2013, 15 (5), 1326-1330. https://doi.org/10.1039/C3GC37030E.

(16) Abbott, A. P.; Cullis, P. M.; Gibson, M. J.; Harris, R. C.; Raven, E. Extraction of Glycerol from Biodiesel into a Eutectic Based Ionic Liquid. Green Chem. 2007, 9, 868-872. https://doi.org/10.1039/b702833d.

(17) Hayyan, M.; Mjalli, F. S.; Hashim, M. A.; AlNashef, I. M. A Novel Technique for Separating Glycerine from Palm Oil-Based Biodiesel Using Ionic Liquids. Fuel Process. Technol. 2010, 91, 116-120. https://doi.org/10.1016/j.fuproc.2009.09.002.

(18) H.G. Morrison; Sun, C. C.; Neervannan, S. Characterization of Thermal Behavior of Deep Eutectic Solvents and Their Potential as Drug Solubilization Vehicles. Int. J. Pharm. 2009, 378, 136-139.

(19) Gunasekara, S. N.; Pan, R.; Chiu, J. N.; Martin, V. Polyols as Phase Change Materials 
for Surplus Thermal Energy Storage. Appl. Energy 2016, 162, 1439-1452. https://doi.org/10.1016/j.apenergy.2015.03.064.

(20) Wahid, M. A.; Hosseini, S. E.; Hussen, H. M.; Akeiber, H. J.; Saud, S. N.; Mohammad, A. T. An Overview of Phase Change Materials for Construction Architecture Thermal Management in Hot and Dry Climate Region. Appl. Therm. Eng. 2017, 112, 1240-1259. https://doi.org/10.1016/j.applthermaleng.2016.07.032.

(21) Fernandez, L.; Silva, L. P.; Martins, M. A. R.; Ferreira, O.; Ortega, J.; Pinho, S. P.; Coutinho, J. A. P. Indirect Assessment of the Fusion Properties of Choline Chloride from Solid-Liquid Equilibria Data. Fluid Phase Equilib. 2017, 448, 9-14. https://doi.org/10.1016/j.fluid.2017.03.015.

(22) Daubert, T. E.; Sibul, H. M.; Stebbins, C. C.; Danner, R. P.; Rowley, R. L.; Adams, M. E.; Wilding, W. V; Marshall, T. L. Physical and Thermodynamic Properties of Pure Chemicals: DIPPR: Data Compilation: Core + Supplements 1-10; Taylor \& Francis, 2000.

(23) Jabrane, S.; Létoffé, J. M.; Claudy, P. Study of the Thermal Behaviour of 1,3Propanediol and Its Aqueous Solutions. Thermochim. Acta 1998, 311, 121-127. https://doi.org/10.1016/S0040-6031(97)00416-4.

(24) Jesus, A. J. L.; Tomé, L. I. N.; Eusébio, M. E.; Redinha, J. S. Enthalpy of Sublimation in the Study of the Solid State of Organic Compounds. Application to Erythritol and Threitol. J. Phys. Chem. B 2005, 109, 18055-18060. https://doi.org/10.1021/jp051621n.

(25) NIST Chemistry WebBook http://webbook.nist.gov/ cgi/cbook.

(26) Prausnitz, J. M.; Lichtenthaler, R. N.; Azevedo, E. G. Molecular Thermodynamics of Fluid-Phase Equilibria; 1970; Vol. 2. https://doi.org/10.1016/0021-9614(70)90078-9.

(27) Elliott, J. R.; Lira, C. T. Introductory Chemical Engineering Thermodynamics, 2nd editio.; Prentiche Hall.

(28) Coutinho, J. A. P.; Andersen, S. I.; Stenby, E. H. Evaluation of Activity Coefficient Models in Prediction of Alkane Solid-Liquid Equilibria. Fluid Phase Equilib. 1995, 103 (1), 23-39. https://doi.org/10.1016/0378-3812(94)02600-6.

(29) Crespo, E. A.; Silva, L. P.; Lloret, J. O.; Carvalho, P. J.; Vega, L. F.; Llovell, F.; Coutinho, J. A. P. A Methodology to Parameterize SAFT-Type Equations of State for 
Solid Precursors of Deep Eutectic Solvents: The Example of Cholinium Chloride. Phys. Chem. Chem. Phys. 2019, 21, 15046-15061.

https://doi.org/10.1039/c9cp02548k.

(30) Bagh, F. S. G.; Shahbaz, K.; Mjalli, F. S.; AlNashef, I. M.; Hashim, M. A. Electrical Conductivity of Ammonium and Phosphonium Based Deep Eutectic Solvents:

Measurements and Artificial Intelligence-Based Prediction. Fluid Phase Equilib. 2013, 356, 30-37. https://doi.org/10.1016/j.fluid.2013.07.012.

(31) Collin, R. L. Polymorphism and Radiation Decomposition of Choline Chloride. J. Am. Chem. Soc. 1957, 79, 6086.

(32) Shanley, P.; Collin, R. L. The Crystal Structure of the High Temperature Form of Choline Chloride. Acta Crystallogr. 1961, 14, 79-80.

(33) Meng, X.; Ballerat-Busserolles, K.; Husson, P.; Andanson, J. M. Impact of Water on the Melting Temperature of Urea + Choline Chloride Deep Eutectic Solvent. New J. Chem. 2016, 40, 4492-4499. https://doi.org/10.1039/c5nj02677f.

(34) Silva, L. P.; Fernandez, L.; Conceiçao, J. H. F.; Martins, M. A. R.; Sosa, A.; Ortega, J.; Pinho, S. P.; Coutinho, J. A. P. Design and Characterization of Sugar-Based Deep Eutectic Solvents Using Conductor-like Screening Model for Real Solvents. ACS Sustain. Chem. Eng. 2018, 6, 10724-10734. https://doi.org/10.1021/acssuschemeng.8b02042.

(35) Zhang, Q.; De Oliveira Vigier, K.; Royer, S.; Jérôme, F. Deep Eutectic Solvents: Syntheses, Properties and Applications. Chem. Soc. Rev. 2012, 41, 7108-7146. https://doi.org/10.1039/c2cs35178a.

(36) García, G.; Aparicio, S.; Ullah, R.; Atilhan, M. Deep Eutectic Solvents: Physicochemical Properties and Gas Separation Applications. Energy \& Fuels 2015, 29 (4), 2616-2644. https://doi.org/10.1021/ef5028873.

(37) López-Porfiri, P.; Brennecke, J. F.; Gonzalez-Miquel, M. Excess Molar Enthalpies of Deep Eutectic Solvents (DESs) Composed of Quaternary Ammonium Salts and Glycerol or Ethylene Glycol. J. Chem. Eng. Data 2016, 61, 4245-4251. https://doi.org/10.1021/acs.jced.6b00608.

(38) Francisco M, van den Bruinhorst A, K. M. Low-Transition-Temperature Mixtures (LTTMs): A New Generation of Designer Solvents. Angew. Chemie Int. Ed. 2013, 52, 
$3074-3085$.

(39) Marták, J.; Schlosser, Š. Density, Viscosity, and Structure of Equilibrium Solvent Phases in Butyric Acid Extraction by Phosphonium Ionic Liquid. J. Chem. Eng. Data 2017, 62, 3025-3035. https://doi.org/10.1021/acs.jced.7b00039.

(40) Leron, R. B.; Wong, D. S. H.; Li, M. H. Densities of a Deep Eutectic Solvent Based on Choline Chloride and Glycerol and Its Aqueous Mixtures at Elevated Pressures. Fluid Phase Equilib. 2012, 335, 32-38. https://doi.org/10.1016/j.fluid.2012.08.016.

(41) Abbott, A. P. Application of Hole Theory to the Viscosity of Ionic and Molecular Liquids. ChemPhysChem 2004, 5, 1242-1246.

https://doi.org/10.1002/cphc.200400190.

(42) Crespo, E. A.; Silva, L. P.; Martins, M. A. R.; Bülow, M.; Ferreira, O.; Sadowski, G.; Held, C.; Pinho, S. P.; Coutinho, J. A. P. The Role of Polyfunctionality in the Formation of [Ch]Cl-Carboxylic Acid-Based Deep Eutectic Solvents. Ind. Eng. Chem. Res. 2018, 57, 11195-11209. https://doi.org/10.1021/acs.iecr.8b01249.

(43) Martins, M. A. R.; Crespo, E. A.; Pontes, P. V. A.; Silva, L. P.; Bülow, M.; Maximo, G. J.; Batista, E. A. C.; Held, C.; Pinho, S. P.; Coutinho, J. A. P. Tunable Hydrophobic Eutectic Solvents Based on Terpenes and Monocarboxylic Acids. ACS Sustain. Chem. Eng. 2018, 6, 8836-8846. https://doi.org/10.1021/acssuschemeng.8b01203.

(44) D’Agostino, C.; Harris, R. C.; Abbott, A. P.; Gladden, L. F.; Mantle, M. D. Molecular Motion and Ion Diffusion in Choline Chloride Based Deep Eutectic Solvents Studied by $1 \mathrm{H}$ Pulsed Field Gradient NMR Spectroscopy. Phys. Chem. Chem. Phys. 2011, 13, 21383-21391. https://doi.org/10.1039/c1cp22554e.

(45) Harifi-Mood, A. R.; Buchner, R. Density, Viscosity, and Conductivity of Choline Chloride + Ethylene Glycol as a Deep Eutectic Solvent and Its Binary Mixtures with Dimethyl Sulfoxide. J. Mol. Liq. 2017, 225, 689-695. https://doi.org/10.1016/j.molliq.2016.10.115.

(46) Crespo, E. A.; Costa, J. M. L.; Palma, A. M.; Soares, B.; Martín, M. C.; Segovia, J. J.; Carvalho, P. J.; Coutinho, J. A. P. Thermodynamic Characterization of Deep Eutectic Solvents at High Pressures. Fluid Phase Equilib. 2019, 500, 112249-112252. https://doi.org/10.1016/j.fluid.2019.112249.

(47) Yadav, A.; Trivedi, S.; Rai, R.; Pandey, S. Densities and Dynamic Viscosities of 
(Choline Chloride+glycerol) Deep Eutectic Solvent and Its Aqueous Mixtures in the Temperature Range (283.15-363.15)K. Fluid Phase Equilib. 2014, 367, 135-142. https://doi.org/10.1016/j.fluid.2014.01.028.

(48) Florindo, C.; Oliveira, F. S.; Rebelo, L. P. N.; Fernandes, A. M.; Marrucho, I. M. Insights into the Synthesis and Properties of Deep Eutectic Solvents Based on Cholinium Chloride and Carboxylic Acids. ACS Sustain. Chem. Eng. 2014, 2, 24162425. https://doi.org/10.1021/sc500439w.

(49) Alomar, M. K.; Hayyan, M.; Alsaadi, M. A.; Akib, S.; Hayyan, A.; Hashim, M. A. Glycerol-Based Deep Eutectic Solvents: Physical Properties. J. Mol. Liq. 2016, 215, 98-103. https://doi.org/10.1016/j.molliq.2015.11.032.

(50) Siongco, K. R.; Leron, R. B.; Li, M. H. Densities, Refractive Indices, and Viscosities of N,N-Diethylethanol Ammonium Chloride-Glycerol or -Ethylene Glycol Deep Eutectic Solvents and Their Aqueous Solutions. J. Chem. Thermodyn. 2013, 65, 6572. https://doi.org/10.1016/j.jct.2013.05.041.

(51) Sarmad, S.; Xie, Y.; Mikkola, J. P.; Ji, X. Screening of Deep Eutectic Solvents (DESs) as Green CO2 Sorbents: From Solubility to Viscosity. New J. Chem. 2016, 41, 290301. https://doi.org/10.1039/c6nj03140d.

(52) Gabriele, F.; Chiarini, M.; Germani, R.; Tiecco, M.; Spreti, N. Effect of Water Addition on Choline Chloride/Glycol Deep Eutectic Solvents: Characterization of Their Structural and Physicochemical Properties. J. Mol. Liq. 2019, 291, 111301. https://doi.org/10.1016/j.molliq.2019.111301.

(53) Hammond, O. S.; Bowron, D. T.; Edler, K. J. The Effect of Water upon Deep Eutectic Solvent Nanostructure: An Unusual Transition from Ionic Mixture to Aqueous Solution. Angew. Chemie 2017, 129, 9914-9917. https://doi.org/10.1002/ange.201702486.

(54) Ma, C.; Laaksonen, A.; Liu, C.; Lu, X.; Ji, X. The Peculiar Effect of Water on Ionic Liquids and Deep Eutectic Solvents. Chem. Soc. Rev. 2018, 47, 8685-8720. https://doi.org/10.1039/c8cs00325d.

(55) Martins, M. A. R.; Silva, L. P.; Schaeffer, N.; Abranches, D. O.; Maximo, G. J.; Pinho, S. P.; Coutinho, J. A. P. Greener Terpene-Terpene Eutectic Mixtures as Hydrophobic Solvents. ACS Sustain. Chem. Eng. 2019, 7, 17414-17423. https://doi.org/10.1021/acssuschemeng.9b04614. 
(56) Jessop, P. G.; Jessop, D. A.; Fu, D.; Phan, L. Solvatochromic Parameters for Solvents of Interest in Green Chemistry. Green Chem. 2012, 14, 1245-1259. https://doi.org/10.1039/c2gc16670d.

(57) Pandey, A.; Pandey, S. Solvatochromic Probe Behavior within Choline ChlorideBased Deep Eutectic Solvents: Effect of Temperature and Water. J. Phys. Chem. B 2014, 118, 14652-14661. https://doi.org/10.1021/jp510420h.

(58) Florindo, C.; McIntosh, A. J. S.; Welton, T.; Branco, L. C.; Marrucho, I. M. A Closer Look into Deep Eutectic Solvents: Exploring Intermolecular Interactions Using Solvatochromic Probes. Phys. Chem. Chem. Phys. 2017, 20, 206-213. https://doi.org/10.1039/c7cp06471c.

(59) Teles, A. R. R.; Capela, E. V.; Carmo, R. S.; Coutinho, J. A. P.; Silvestre, A. J. D.; Freire, M. G. Solvatochromic Parameters of Deep Eutectic Solvents Formed by Ammonium-Based Salts and Carboxylic Acids. Fluid Phase Equilib. 2017, 448, 1521. https://doi.org/10.1016/j.fluid.2017.04.020. 


\section{For Table of Contents Use Only}
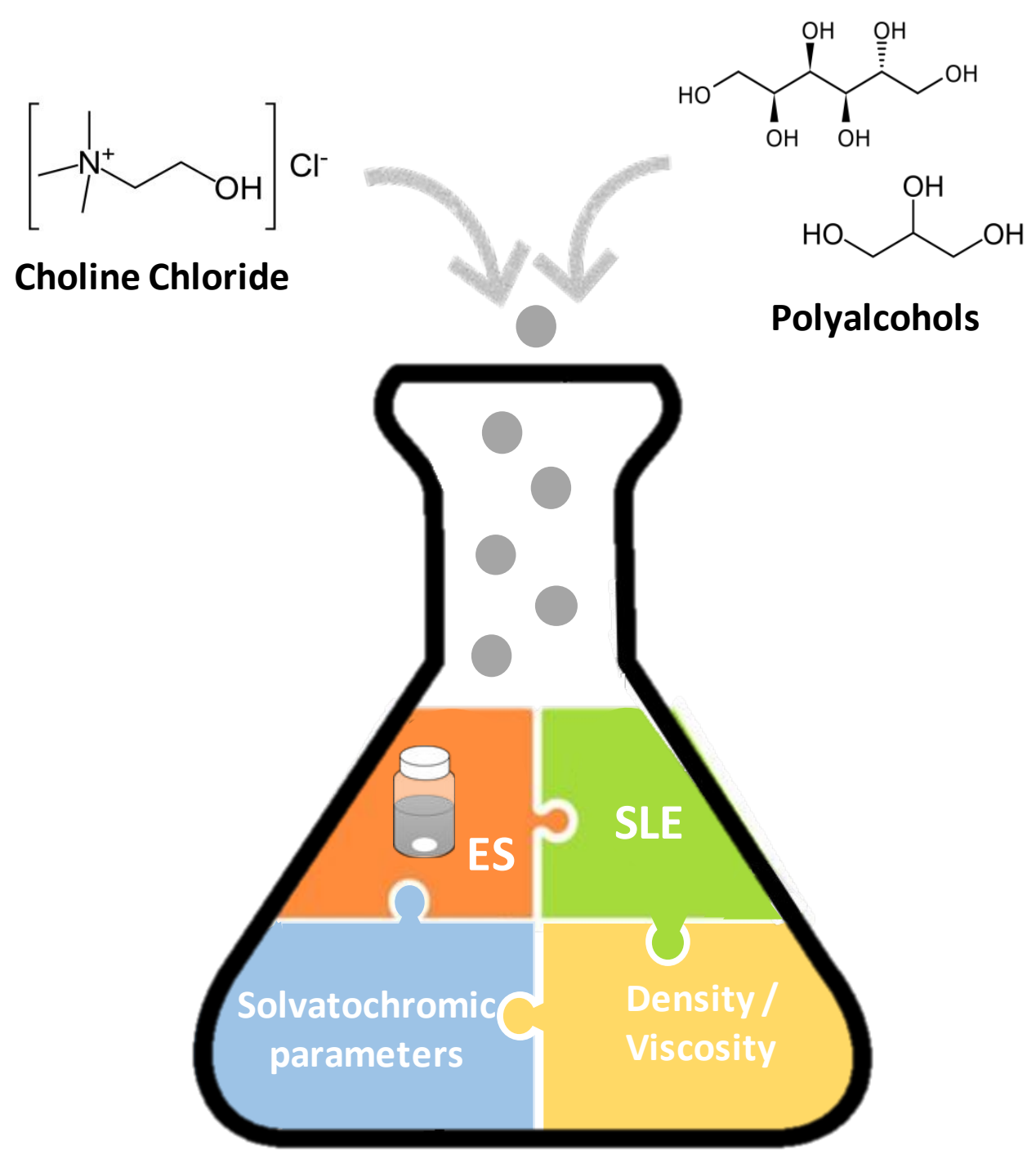

\section{Synopsis}

Design and characterization of sustainable eutectic solvents formed by choline chloride and polyalcohols. 